\title{
Two issues with competition in healthcare
}

\author{
Lucy A Reynolds research fellow \\ London School of Hygiene and Tropical Medicine, London WC1E 7HT, UK
}

Two issues are important in any discussion of competition in healthcare.

Firstly, while "any qualified provider" (AQP) now replaces "any willing provider" (AWP), comparison of the mid-2010 Department of Health procurement guidance with this month's NHS Confederation advice shows that their commissioning processes are identical. ${ }^{1}$ The market based AWP commissioning process conforms to EU public procurement regulations. "AQP" is meaningless in EU law, so the AWP process has merely been renamed, with no new qualification procedure.

Secondly, the current NHS reform was delineated in 1987-8, in papers by MPs Redwood, Letwin (both ex-directors of Rothschilds' Privatisation Unit), Willetts, and Peet. All asserted without evidence that competition would benefit UK healthcare. In 2005, Lansley proclaimed "maximising competition" as the "principle of NHS reform," and now he prescribes competition for every NHS ill.

But 24 years after such reforms were designed, supporters can justify them only by citing a few recent observational studies claiming that competition improves health outcomes, although confounding may explain these effects. ${ }^{3}$

Competition based reform involves activity based fees for service (misnamed "payment by results"). Financial incentives raise doctors' activity levels, ${ }^{4}$ but this does not translate into better health outcomes. If doctors paid this way are underprovided in a community, more activity might improve outcomes. If they are overprovided (hence, competition exists), their need to make a living incentivises overtreatment. ${ }^{5}$ No treatment is devoid of adverse effects, so poorer outcomes ensue. ${ }^{6}$ Using fees for service generates undertreatment and overtreatment, with efforts diverted away from people in medical need who cannot pay towards those who can pay but don't necessarily need treatment.

Welfare economics provides the theoretical justification for promoting competition, but this model doesn't fit healthcare. The main problem is information asymmetry: because the patient consults the doctor for advice and accepts the treatment recommended, the supplier controls demand. Combining information asymmetry with fees for service generates supplier induced demand, a phenomenon that absorbed $10-12 \%$ of 2009 US healthcare spending. ${ }^{7}$ This phenomenon disproves the theory that patient choice in a competitive healthcare market limits costs and raises quality.

\section{Competing interests: None declared.}

Reynolds L. "Any willing provider" vs "any qualified provider" in the NHS reform: differen bottle, same contents [electronic response to Lister JRW. NHS reforms: Issues MPs and the media have missed in Lansley's bill]. 2011. www.bmj.com/content/342/bmj.d3194.full/ reply\#bmj_el_266823

2 Health Policy Insight. Text of Labour shadow health secretary John Healey's RSM speech. Editor's blog. 2011. www.healthpolicyinsight.com/?q=node/1124.

3 Stevens $\mathrm{S}$. Is there evidence that competition in healthcare is a good thing? Yes. BMJ 2011;343:d4136. (5 July.)

4 Farrar S, Yi D, Sutton M, Chalkley M, Sussex J, Scott A. Has payment by results affected the way that English hospitals provide care? Difference-in-differences analysis. BMJ 2009;339:b3047.

5 Bennett D, Lauderdale TS, Hung CL. Competing doctors, antibiotic use, and antibiotic resistance in Taiwan. 2008. http://chess.uchicago.edu/events/hew/fallo8/bennett.pdf.

6 Gawande A. The cost conundrum. New Yorker 2009. www.newyorker.com/reporting/2009/ 06/01/090601fa_fact_gawande?currentPage=all.

7 Waste measurements: US healthcare spending. Economist 2011. www.economist.com/ blogs/dailychart/2011/06/us-health-care-spending . 